PALABRAS CLAVE

Empleo

Mercado de trabajo

Ingresos familiares

Pobreza

Mitigación de la pobreza

Medición

Análisis de datos

Datos estadísticos

Encuestas de hogares

América Latina

Simone Cecchini

Oficial de Asuntos Sociales,

División de Desarrollo Social,

CEPAL

œ simone.cecchini@cepal.org

Andras Uthoff

Director,

División de Desarrollo Social,

CEPAL

$\propto$ andras.uthoff@cepal.org
REVISTA DE LA CEPAL 94 - ABRIL 2008

\section{Pobreza y empleo en América Latina: 1990-2005}

\author{
Simone Cecchini y Andras Uthoff
}

¿ ué factores explican la reducción de la pobreza que se observa en América Latina desde el año 1990? Este artículo investiga los principales factores que han influido en ese descenso de la pobreza en la región, entre los cuales destacan en particular el empleo y las remuneraciones del trabajo. Con datos extraídos de encuestas de hogares se analiza de qué manera los cambios en la población en edad de trabajar, en su participación en la actividad económica, en las tasas de ocupación y en los ingresos laborales y de otras fuentes, afectan el ingreso per cápita de las familias que se hallan en los distintos deciles de la distribución del ingreso y, por ende, los índices de pobreza. 


\section{I}

\section{Introducción}

La mejor manera —y la más digna— de que las familias latinoamericanas salgan de la pobreza y se mantengan fuera de ella es la participación de sus miembros activos en el mercado de trabajo y su ocupación en empleos bien remunerados. Por lo tanto, para reducir la pobreza el crecimiento económico tiene que traducirse en mayores ingresos familiares mediante la generación de empleos productivos adecuadamente remunerados.

La importante contribución de los factores laborales a la reducción de la pobreza ha sido consagrada en el ámbito de las Naciones Unidas en una nueva meta del Milenio: "Lograr el empleo pleno y productivo y el trabajo decente para todos, en particular para las mujeres y los jóvenes" (Meta 1.B). Esta nueva meta, que fue propuesta por el Secretario General de las Naciones Unidas en el 2006 y que ha entrado en vigor en el 2008, ha sido incluida en el primer objetivo de desarrollo del Milenio, "erradicar la pobreza extrema y el hambre", justamente para recalcar la estrecha relación que existe entre el mercado de trabajo y el mejoramiento de los aspectos materiales del bienestar de las personas.

En cuanto a la magnitud del problema de la pobreza en América Latina, las más recientes estimaciones de la CEPAL indican que en el 2006 un 37\% de la población de la región (194 millones de personas) se hallaba en situación de pobreza y un $13 \%$ de la población (71 millones de personas) en condiciones de pobreza extrema. Aunque sigue siendo demasiado alta la cantidad de latinoamericanos que viven con muy escasos recursos, la tasa de pobreza indicada significa un descenso significativo con respecto a su nivel de 1990, cuando era pobre un $48 \%$ de la población. Algo parecido sucede con la tasa de indigencia, que descendió más de nueve puntos porcentuales con respecto al 22,5\% observado hace una década y media (CEPAL, 2007d). En todo caso, los resultados regionales esconden grandes diferencias entre países, varios de los cuales no lograron aminorar la pobreza en los últimos 15 años.

El propósito de este artículo es investigar cuáles son los factores que han contribuido a la disminución

$\square$ Los autores agradecen a Irma Arriagada, Reynaldo Bajraj, Christoph Ernst, Ernesto Espíndola, Juan Carlos Feres, Marco Galván, Martín Hopenhayn, Arturo León, Fernando Medina, Pablo Villatoro, Jorge Rodríguez, Nora Ruedi y Jürgen Weller por sus valiosos comentarios a versiones anteriores de este trabajo. de la pobreza en América Latina a partir de 1990. ${ }^{1}$ Para hacerlo se propone una metodología de desagregación del cambio ocurrido en el ingreso per cápita de los hogares más vulnerables, con el fin de analizar de qué manera las variables laborales - así como las variables demográficas y las estructuras y comportamientos familiares- han contribuido a reducir la incidencia de la pobreza en los países de la región, al elevar sus ingresos familiares per cápita por sobre aquel correspondiente a la línea de pobreza. Dada la creciente importancia en la región de las transferencias estatales focalizadas en las familias de menores ingresos, en el análisis se incluye también una variable - los ingresos no laborales - que da cuenta de los programas estatales de transferencias condicionadas a las familias, así como de diversas fuentes de ingreso, entre ellas las remesas, pensiones o jubilaciones.

$\mathrm{El}$ análisis realizado en este documento cubre el período 1990-2005, es decir, los primeros 15 de los 25 años de que disponen los países de la región para cumplir con la primera meta de los objetivos de desarrollo del Milenio - la reducción a la mitad entre 1990 y 2015 del porcentaje de personas que viven en extrema pobreza. Aunque se reconoce que la pobreza es un fenómeno complejo y multidimensional, que abarca privaciones en muchos aspectos del bienestar individual y colectivo (CEPAL, 2003; Sen, 1985), esta investigación utiliza indicadores de ingresos monetarios, tal como se hace para el seguimiento de la primera meta del Milenio. En particular, sigue la metodología usada por la CEPAL y se refiere a la pobreza en tanto privaciones en la capacidad de las personas de satisfacer sus necesidades más básicas. ${ }^{2}$

\footnotetext{
${ }^{1}$ Este artículo se inserta en un renovado interés por el análisis de los efectos de las variables laborales y demográficas sobre la reducción de la pobreza. Entre los estudios recientes de los factores determinantes de los cambios en la pobreza medida por los ingresos se hallan el de Kakwani, Neri y Son (2006) en el caso de Brasil y el de Núñez, Ramírez y Cuesta (2006) para Colombia.

${ }^{2}$ El enfoque utilizado por la CEPAL para estimar la pobreza consiste en clasificar como "pobre" a una persona cuando el ingreso por habitante de su hogar es inferior al valor de la "línea de pobreza" o monto mínimo necesario para satisfacer sus necesidades esenciales. Las líneas de pobreza, expresadas en la moneda de cada país, se determinan a partir del valor de una canasta de bienes y servicios, empleando el método del "costo de las necesidades básicas". Para mayor información, véase CEPAL (2007d), recuadro I.1.
} 
Considerando que la noción de "pobreza total"3 ocupa un lugar predominante en los debates sobre el bienestar social en la región y que CEPAL (2005a) sugirió una meta más ambiciosa para América Latina - reducir a la mitad el porcentaje de población en situación de pobreza total y no sólo el porcentaje de población con mayores carencias-, en este trabajo nos enfocaremos en todos los pobres y no exclusivamente en los indigentes. Se reconoce así que las personas cuyos ingresos per cápita se encuentran por arriba pero muy cercanas a la línea de indigencia están en una situación muy vulnerable, dado que pueden fácilmente caer en la extrema pobreza por posibles crisis económicas o por circunstancias que merman temporal o permanentemente los recursos familiares (enfermedades, discapacidad de un perceptor de ingreso en la familia, nacimientos, defunciones y otras).

En la sección II, al considerar los factores que contribuyen a reducir la pobreza, se propone una metodología simple de desagregación que utiliza microdatos de encuestas de hogares sobre 16 países de la región. Con esta base, en la sección III se analiza de qué manera los cambios en el ingreso per cápita de las personas pertenecientes a los distintos deciles de la distribución del ingreso - y en consecuencia los índices de pobreza— son explicados por cambios en el número de ocupados dentro de la población, en el ingreso laboral por ocupado y en los ingresos no laborales de la población total. Finalmente, en la sección IV se resumen los resultados del estudio y se examinan algunas connotaciones de política.

\section{II}

\section{Factores asociados a la reducción de la pobreza}

\section{Mercado de trabajo}

En América Latina, el empleo es la principal fuente de ingreso de los hogares, ya que las remuneraciones provenientes del trabajo representan en promedio más del 80\% de sus ingresos (CEPAL, 2007c). Sin embargo, el subempleo y el desempleo, las altas tasas de dependencia que limitan la participación de las mujeres en edad de trabajar, los bajos niveles de capital humano y la poca productividad de muchas ocupaciones son la causa de altos índices de pobreza. En particular, CEPAL (2007c) argumenta que en la región el deterioro de la calidad de los puestos de trabajo ha debilitado la relación entre crecimiento del producto interno bruto (PIB) y disminución de la pobreza. Por ende, la creación de empleo y el aumento de la productividad laboral —especialmente entre los pobres- constituyen los mecanismos fundamentales de trasmisión entre el crecimiento económico y la reducción de la pobreza y permiten traducir el crecimiento en mayores ingresos para los pobres (Islam, 2004; Osmani, 2002).

El crecimiento económico sostenido de los últimos años ha tenido repercusiones favorables en los resultados de los mercados de trabajo latinoamericanos. Desde

\footnotetext{
3 "Pobreza total" se refiere simplemente a la suma del porcentaje (o número) de personas indigentes y pobres no indigentes.
}

el 2003 la tasa de desempleo regional ha tenido una tendencia a la baja y en el 2007 llegó a 8\% — con una caída de 0,6 puntos porcentuales respecto al 2006-, a pesar de que ha habido importantes incrementos del número de ocupados así como una acelerada incorporación de mujeres al mercado laboral. Asimismo, se ha observado un aumento de los salarios reales del sector formal (CEPAL, 2007b; OIT, 2007).

Pero los resultados favorables del período 20032007 no debieran ocultar la persistencia de problemas estructurales que inciden sobre la pobreza. La tasa de desempleo regional todavía supera en dos puntos porcentuales el nivel de 1990, en parte a causa del aumento de la participación en la actividad económica. El número de desempleados —especialmente entre los pobres - es todavía muy alto, situándose alrededor de los 17 millones de personas en las áreas urbanas de América Latina (CEPAL, 2007b). El sector informal ${ }^{4}$ sigue siendo de gran magnitud, estimándose que en el 2005 los empleos informales absorbían el 48,5\% del total de los ocupados urbanos (oIT, 2006), y la cobertura de la protección en salud y pensiones de los

\footnotetext{
${ }^{4}$ La Organización Internacional del Trabajo (OIT) define al sector informal como la suma de trabajadores no profesionales que trabajan por cuenta propia, empleados domésticos, trabajadores familiares no remunerados y trabajadores de empresas de hasta cinco empleados (OIT, 2006).
} 
trabajadores de la región es muy baja. Además, aún se observan bajas tasas de participación de las mujeres y altas tasas de desempleo en comparación con las de los hombres, así como altos niveles de desigualdad de los ingresos laborales. En todos los países de la región, las mujeres perciben menores ingresos salariales que los hombres, aunque tengan igual escolaridad y experiencia (CEPAL, 2007a). Asimismo, la tasa de desempleo juvenil duplica con creces la de los adultos: un $16 \%$ comparado con un $7 \%$ a inicios de la presente década (Weller, 2006).

\section{Reproducción intergeneracional de la pobreza}

Existen dos factores principales que llevan a la reproducción y perpetuación de la pobreza a lo largo del tiempo. De una parte, los bajos ingresos de los trabajadores que componen las familias pobres, lo cual se explica por una escasa acumulación de capital humano y baja productividad. De otra, las elevadas tasas de dependencia demográfica en esas familias, lo que obliga a repartir el ingreso entre un mayor número de personas. Esto significa que los pobres no solo perciben menores ingresos laborales, sino que deben utilizar esos ingresos para la supervivencia de un mayor número de personas que son dependientes. En ambos casos, pero sobre todo en el segundo, los comportamientos y las decisiones de las familias tienen un papel fundamental.

El escaso capital humano de los miembros activos de los hogares pobres se debe a sus limitadas opciones educativas y también a las decisiones de estas familias respecto a mantener o no sus niños en el sistema escolar. Esto explica, al menos parcialmente, sus restringidas oportunidades de empleo y representa un círculo vicioso que reproduce la pobreza: por un lado, quienes viven en familias pobres tienen una formación deficiente para el trabajo y acceden a empleos precarios; por otro, los niños y jóvenes de estos hogares tienen pocas oportunidades de educarse y capacitarse con calidad (CEPAL, 2007d), carecen de un adecuado capital social y por lo tanto acceden a ocupaciones de baja productividad cuando ingresan al mercado de trabajo. Entre los pobres, de hecho, se da con mayor frecuencia el desempleo y los que logran emplearse lo hacen con menos frecuencia como asalariados y en empleos formales (gráfico 1).

Las posibilidades de las familias de generar mayores ingresos aumentan cuando las decisiones sobre su tamaño y composición - así como sobre la participación de sus miembros en el mercado de trabajo - incrementan la proporción de miembros en edad de trabajar respecto de los dependientes. Los resultados de estas decisiones tienen un componente de inercia, que se relaciona con la etapa del ciclo

GRÁFICO 1

América Latina (18 países, promedio simple): tasa de desempleo, tasa de ocupación y
porcentajes de trabajadores en el sector formal de la economía (respecto del total de los
ocupados), por deciles de ingreso, total nacional, alrededor del $2005^{\mathrm{a}, \mathrm{b}}$

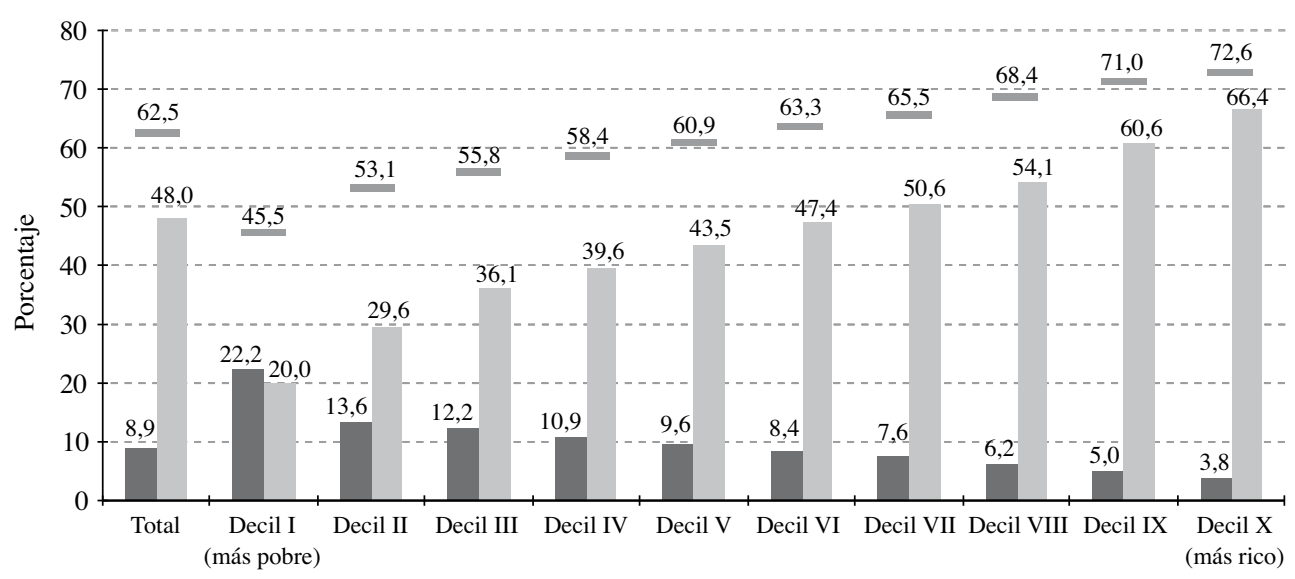

Tasa de desempleo $\square$ Trabajadores en el sector formal $\square$ Tasa de ocupación

Fuente: elaboración propia, sobre la base de las encuestas de hogares de los respectivos países.

a Los datos de Argentina, Bolivia, Ecuador, Paraguay y Uruguay se refieren solamente a la población urbana y no al total nacional.

b La tasa de ocupación se refiere al número de ocupados dividido por la población en edad de trabajar (o/PET, tasa de ocupación bruta). 
de vida familiar y con el cambio demográfico vinculado a la fecundidad, y también un componente más coyuntural, que tiene que ver con decisiones de localización, composición y rupturas familiares y con nuevas modalidades de convivencia. Los cambios en la estructura de la familia y los quiebres familiares pueden modificar la relación de dependencia, ya sea porque los miembros activos abandonan el hogar, o porque los matrimonios más jóvenes se hacen cargo de los inactivos, o bien, por la constitución de nuevas uniones familiares para compartir gastos.

Las familias pobres tienen más miembros que las no pobres y la mayor parte de ellos son niños, lo cual causa altas tasas de dependencia. Aunque la relación de dependencia está descendiendo en todos los países de la región, propiciando así el denominado "bono demográfico", 5 esta aún se mantiene elevada en los estratos socioeconómicos más vulnerables debido a sus mayores niveles de fecundidad (CEPAL, 2005b). En la actualidad, las familias con mayor cantidad de miembros se ubican principalmente en el $20 \%$ de hogares más pobres, mientras que los hogares de menor tamaño se concentran en el quintil superior de ingresos. En América Latina, el tamaño medio de las familias urbanas que pertenecen al quintil más pobre de la distribución del ingreso tienen en promedio entre 4,2 y 6,2 miembros (República Dominicana y Guatemala, respectivamente), mientras que el tamaño medio de las familias que pertenecen al quintil más rico varía entre 2,1 y 4 miembros (Uruguay y Nicaragua, respectivamente) (Sunkel, 2006).

Al respecto, se debe considerar que el tamaño y estructura de las familias latinoamericanas dependen de distintos factores, como las etapas de transición demográfica en que se halla el país, su nivel de desarrollo económico y la crisis del modelo de familia patriarcal. Por ejemplo, en los países en etapas avanzadas de la transición demográfica es más alta la proporción de familias nucleares constituidas por parejas mayores sin hijos y más alto también el número de hogares unipersonales correspondientes a personas mayores y a jóvenes con autonomía económica. En los países en etapas de transición demográfica moderada y plena se encuentran más familias con hijos pequeños. A su vez, en los países de menor nivel de desarrollo hay una mayor proporción de familias nucleares monoparentales, así como de familias extensas y compuestas ${ }^{6}$ (Arriagada, 2004; CEPAL 2007a).

\footnotetext{
${ }^{5}$ Véase más adelante la sección IV.

${ }^{6}$ Las familias extensas están integradas por padre o madre o ambos, con o sin hijos y otros parientes; las familias compuestas, por padre o madre o ambos, con o sin hijos, con o sin otros parientes u otras
}

También se debe considerar la incidencia de factores culturales asociados a la división del trabajo al interior de los hogares, que restringen fuertemente la participación de la mujer en la actividad económica. Alrededor del 2005, en América Latina la participación de las mujeres en la actividad económica era de $37 \%$ en el decil más pobre y de $61 \%$ en el de mayores recursos. Los hombres, en cambio, exhibían una diferencia mínima: la participación de los más pobres era de $76 \%$ y la de los más ricos, de $80 \%$ (gráfico 2). A lo anterior se suma la reducida cobertura de la economía del cuidado, que ha impedido, en el caso de las mujeres, compatibilizar el cuidado de niños y ancianos y las labores del hogar con el trabajo remunerado.

En síntesis, baja productividad, baja participación, episodios frecuentes de desempleo y alta dependencia demográfica concurren a multiplicar los eslabones de la escasez en un mismo hogar que vive bajo la línea de pobreza.

\section{Desagregación del ingreso per cápita}

Las tendencias de los indicadores de pobreza pueden ser analizadas mediante la identificación de la importancia relativa de los cambios en los mercados de trabajo, en las estructuras demográficas y en las estructuras y comportamientos familiares. La incidencia de la pobreza podrá variar debido a cambios que derivan de mejoras en el ingreso laboral por ocupado - variable sustitutiva de la productividad laboral-y en el ingreso no laboral, y a cambios en el número de ocupados en relación con la población total (o "tasa de ocupación global") —que surgen de la interacción entre las variaciones en las estructuras y decisiones familiares y el comportamiento de los miembros del hogar en el mercado de trabajo. A igualdad de otras condiciones, si el ingreso laboral por ocupado aumenta, en particular en los deciles más bajos de la distribución del ingreso, esto contribuirá a reducir la pobreza monetaria. De manera similar, un aumento en el número de ocupados en relación con la población total o un aumento de los ingresos no laborales contribuirán a la disminución del porcentaje de personas que viven por debajo de la línea de pobreza.

El ingreso per cápita de una población $(Y / N)$-indicador que permite discriminar a las familias según su pobreza monetaria - mide su capacidad para generar ingresos en el mercado de trabajo, así como para captar

personas no parientes — sin incluir el servicio doméstico que vive con la familia ni sus familiares. 
América Latina (18 países, promedio simple): tasa de participación en la actividad económica por deciles de ingreso, mujeres y hombres, total nacional, alrededor del $2005^{a}$

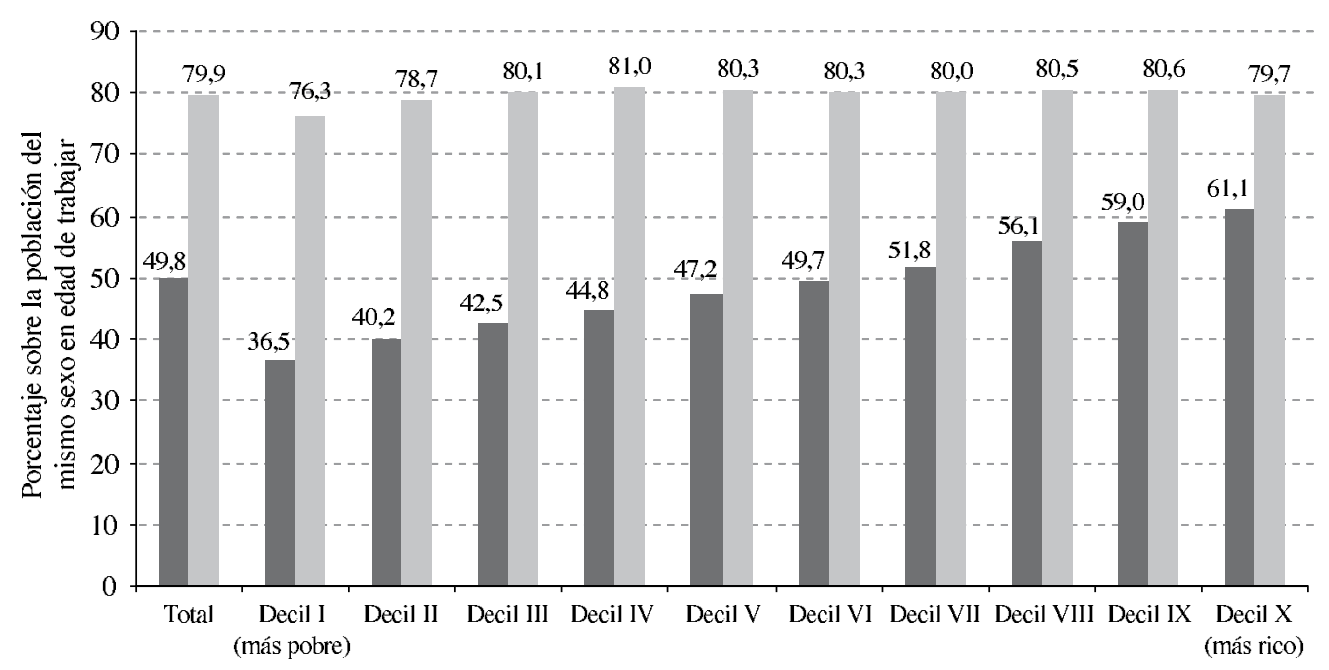

$\square$ Mujeres $\square$ Hombres

Fuente: elaboración propia, sobre la base de las encuestas de hogares de los respectivos países.

a Los datos de Argentina, Bolivia, Ecuador, Paraguay y Uruguay se refieren solamente a la población urbana y no al total nacional.

ingresos de otras fuentes, tales como transferencias estatales, remesas o rentabilidad de la propiedad de capital financiero. Este indicador es analizado distinguiendo tres factores principales:

- Tasa de ocupación global (o número de ocupados $O$ dividido por la población total $N$ ): medida que abarca la composición por edades de una población y su participación en el mercado de trabajo, así como la capacidad de una economía de absorber la fuerza de trabajo. Fue adoptado en 2008 como nuevo indicador oficial para el seguimiento de los objetivos de desarrollo del Milenio, y es conocido también con el nombre de "relación empleo-producto".

- Ingreso laboral por ocupado $(Y L / O)$ : medida que aproxima la productividad laboral.

- Ingreso no laboral per cápita $(Y N L / N)$ : medida que se refiere a una variedad de fuentes de ingresos, que van desde las transferencias del Estado y de privados a los hogares hasta la renta de la propiedad y el ingreso disponible por concepto de arriendo imputado.

$$
\frac{Y}{N}=\left(\frac{O}{N} \times \frac{Y L}{O}\right)+\frac{Y N L}{N}
$$

La tasa de ocupación global puede a su vez ser desagregada en los siguientes elementos:
- Tasa de dependencia demográfica: razón entre la población en edad de trabajar PET y la población total $N$.

- Tasa de participación: población económicamente activa $P E A$ dividida por la población en edad de trabajar PET y

- Tasa de ocupación neta: número de ocupados $O$ dividido por la población económicamente activa $P E A$; es el complemento de la tasa de desocupación (O/PEA = 1 - tasa de desocupación).

$$
\frac{Y}{N}=\left[\left(\frac{P E T}{N} \times \frac{P E A}{P E T} \times \frac{O}{P E A}\right) \times\left(\frac{Y L}{O}\right)\right]+\frac{Y N L}{N}
$$

Para analizar las tendencias del ingreso per cápita en el tiempo —entre 1990 y el 2005- se calculan los valores de sus tres componentes principales - la tasa de ocupación global, el ingreso laboral por ocupado y el ingreso no laboral per cápita- según la siguiente fórmula:

$$
\begin{gathered}
\frac{Y}{N}(2005)-\frac{Y}{N}(1990)=\left[\frac{Y L}{O}(2005) \times\left(\frac{O}{N}(2005)-\frac{O}{N}(1990)\right)\right]+ \\
{\left[\frac{O}{N}(1990) \times\left(\frac{Y L}{O}(2005)-\frac{Y L}{O}(1990)\right)\right]+\left(\frac{Y N L}{N}\right)(2005)-\left(\frac{Y N L}{N}\right)(1990)}
\end{gathered}
$$


Los aumentos en el número de ocupados, en los ingresos laborales por ocupado y en el ingreso proveniente de otras fuentes contribuirán a reducir la pobreza monetaria en las familias inicialmente pobres.

\section{Efectos del ciclo económico}

A lo largo del ciclo económico, el ingreso laboral por ocupado es determinado en gran parte por la productividad laboral y tiende por lo tanto a ser procíclico —o sea, a aumentar durante períodos de expansión económica y a disminuir durante las recesiones. El grado en que los ingresos son procíclicos varía según la importancia relativa de los mecanismos de ajuste en un mercado de trabajo específico, dado que los ajustes pueden ser más por cantidades (empleo/desempleo) o más por precios (salarios). Además, se reconoce que puede haber otros factores que inciden en los ingresos laborales, como el grado de protección y el poder de negociación que tiene la fuerza laboral (niveles de sindicalización, existencia de negociación colectiva y otros aspectos).

Los ingresos no laborales, que incluyen transferencias tales como remesas, ingresos en especie e ingresos por alquileres, no son necesariamente procíclicos, y las transferencias públicas a las familias pobres deberían ser contracíclicas (o sea, deberían aumentar durante las crisis).

La tasa de ocupación neta tiene un fuerte componente procíclico, ya que se espera que el número de ocupados se acreciente junto con aumentar el PIB y disminuya en períodos de recesión. ${ }^{7}$ Sin embargo, en etapas de expansión económica, la población económicamente activa (el denominador del indicador) también puede aumentar, ya que más personas en edad de trabajar podrían querer incorporarse al mercado de trabajo. Por esta razón, podría verse neutralizado el efecto procíclico.

La tasa de participación indica el comportamiento de la población en edad de trabajar respecto de su decisión de participar en la actividad económica. En

\footnotetext{
${ }^{7}$ Asimismo, durante períodos de caída del PIB es previsible que junto con la tasa de desempleo aumente la proporción de empleo en el sector informal (OIT, 2006).
}

otras palabras, mide la oferta de trabajo, relacionando la cantidad de personas que trabajan o desean trabajar (los activos) con todos los que estarían en condición de hacerlo (Navarrete, 2005). ${ }^{8}$ Las personas enfrentan necesidades, incentivos y limitaciones para participar en el mercado de trabajo. Cuando carecen de calificaciones, son inválidas o necesitan desarrollar roles incompatibles con el trabajo fuera del hogar, prevalecen las limitaciones u otras razones que fácilmente llevan a muchas a abandonar la búsqueda de trabajo. En otros casos los incentivos son suficientes para motivar a algunas personas a considerar la posibilidad de incorporarse al mercado de trabajo, ya que sienten que su tiempo es mejor valorado en dicho mercado que fuera de él. Otras personas ingresan al mercado laboral porque enfrentan necesidades básicas que las fuerzan a desarrollar cualquier tipo de actividad económica que les permita obtener medios de subsistencia. Como resultado de estos factores, la tasa de participación puede aumentar a medida que amplios sectores de la sociedad (especialmente las mujeres) que se dedicaban al trabajo doméstico no remunerado se incorporan al trabajo remunerado. Sin embargo, dado que las motivaciones derivadas de las necesidades, incentivos y limitaciones difieren para distintos grupos de personas a lo largo del ciclo económico, no siempre es claro el vínculo entre la tasa de participación global y el ciclo económico. ${ }^{9}$

La relación entre la población en edad de trabajar y la población total es un componente estructural que está determinado por las tendencias demográficas, así como por los cambios en las estructuras de las familias. $\mathrm{Al}$ respecto, cabe destacar que la población en edad de trabajar representa solo un potencial de ingresos para la subsistencia de las familias, porque en este segmento hay personas inactivas y entre las activas hay personas ocupadas y desocupadas; asimismo, algunas de las personas ocupadas están plenamente empleadas y otras subempleadas (Uthoff, Vera y Ruedi, 2006).

\footnotetext{
${ }^{8}$ Los "inactivos" son los que no participan en la actividad económica; son mayoritariamente personas que se dedican al trabajo doméstico no remunerado y estudiantes, aunque incluyen también a jubilados, rentistas y personas con discapacidad.

${ }^{9}$ Kakwani, Neri y Son (2006) encontraron que en el período 1995-2004 las tasas de participación de los pobres en Brasil fueron más procíclicas que las tasas correspondientes al total de la población.
} 


\section{III}

\section{Efectos sobre la reducción de la pobreza que tienen los cambios en la tasa global de ocupación $y$ en los ingresos laborales y no laborales}

El análisis de los factores asociados a la reducción de la pobreza se basa en un esquema de descomposición de los ingresos per cápita de los hogares que viven bajo la línea de pobreza; tal esquema considera la proporción de ocupados, el ingreso laboral por ocupado y los ingresos de fuentes no laborales. ${ }^{10}$ En esta lógica, el efecto de los incrementos en el capital humano y de los aumentos en la productividad se manifiesta en el componente de ingresos laborales por ocupado, mientras que la influencia de los cambios demográficos y familiares se expresa en el componente que identifica a los ocupados como proporción de la población total. A su vez, las decisiones de las familias sobre la participación de sus integrantes en el mercado de trabajo están determinadas por el atractivo de los nuevos empleos creados en el mercado de trabajo y por las restricciones que presente la economía del cuidado en los diferentes países.

El cuadro 1 presenta para cada decil de la distribución del ingreso los valores del ingreso familiar per cápita (expresado en múltiplos de la línea de pobreza) y estima la variación de esos valores debida a cambios en el ingreso laboral por ocupado, la tasa de ocupación global y el ingreso no laboral per cápita (véase la fórmula 3 antes citada).

Sobre la base del cuadro anterior, el cuadro 2 agrupa a los países de América Latina según la variación en el período examinado de los tres componentes del ingreso per cápita en los deciles que alrededor de 1990 se encontraban por debajo de la línea de pobreza, y según la variación de la incidencia total de la pobreza en cada país durante dicho período.

\footnotetext{
${ }^{10}$ Para los efectos del análisis de la evolución de la pobreza, importa lo que ocurre - tanto en términos de tendencias del ingreso laboral por ocupado como de la tasa de ocupación global y del ingreso no laboral per cápita — entre los hogares que viven por debajo de la línea de pobreza. Los aumentos en los ingresos medios podrían esconder situaciones que no favorecen a los pobres, tales como mejoras en los deciles más ricos y bajas en los deciles más pobres.
}

\section{Importancia relativa de los factores de cambio en los hogares pobres}

La observación de las tendencias de los factores en los deciles cuyo ingreso medio es igual o inferior a la línea de pobreza lleva a tres consideraciones. En primer lugar, el compromiso con las metas del Milenio ha coincidido con un período caracterizado por el aumento de la proporción de miembros activos de las familias dentro del total de la población pobre, siendo las excepciones más significativas las áreas urbanas de Uruguay y en menor medida el Área Metropolitana de Asunción, en Paraguay. El mejoramiento de la tasa de ocupación global se ha dado principalmente por el decrecimiento de la relación de dependencia demográfica y el incremento de la participación laboral femenina, y en muy pocos casos por el descenso de la tasa de desempleo. En segundo lugar, durante todo el período no se detectan aumentos del ingreso laboral por ocupado que beneficien a las familias más pobres, salvo en Chile, Brasil y Ecuador (áreas urbanas). En tercer lugar, el incremento del ingreso no laboral en los estratos pobres ha sido bastante generalizado, aunque responde a diferentes causas cuyo análisis trasciende el alcance del presente trabajo. Sin una desagregación más detallada de la variedad de fuentes de ingresos incluidas en este tercer componente, no es posible llegar a conclusiones sobre la importancia relativa de los programas estatales de transferencias condicionadas a las familias, las remesas y otras fuentes (como pensiones o jubilaciones). ${ }^{11}$

Solo cinco de los 16 países analizados han logrado importantes reducciones de la pobreza desde principios de los años 1990: los tres beneficiados por mejoras en los ingresos laborales por ocupado (Chile, Brasil, áreas

\footnotetext{
${ }^{11}$ En los últimos años ha sido habitual que las transferencias estatales a las familias de menores ingresos se condicionen a cambios en sus comportamientos, con el propósito de ayudarlas a aumentar su productividad mediante una mayor inversión en capital humano, una mejor asignación de su tiempo o un mayor acceso a activos productivos (CEPAL, 2006). Respecto a los efectos de las remesas sobre la pobreza y la desigualdad, véase CEPAL (2005b).
} 
CUADRO 1

América Latina (16 países): ingreso familiar per cápita y desagregación de su variación según los cambios en los ingresos laborales por ocupado, la tasa global de ocupación y los ingresos no laborales per cápita ${ }^{a}$ (en múltiplos de la línea de pobreza), por decil de la distribución del ingreso, 1989/1995 a 2001/2005

\begin{tabular}{|c|c|c|c|c|c|c|c|c|c|c|c|c|}
\hline País & $\begin{array}{l}\text { Ingreso per } \\
\text { cápita }(\mathrm{Y} / \mathrm{N})\end{array}$ & Total & $\begin{array}{l}\text { Decil } \\
\text { I }\end{array}$ & $\begin{array}{c}\text { Decil } \\
\text { II }\end{array}$ & $\begin{array}{c}\text { Decil } \\
\text { III }\end{array}$ & $\begin{array}{l}\text { Decil } \\
\text { IV }\end{array}$ & $\begin{array}{c}\text { Decil } \\
\text { V }\end{array}$ & $\begin{array}{c}\text { Decil } \\
\text { VI }\end{array}$ & $\begin{array}{c}\text { Decil } \\
\text { VII }\end{array}$ & $\begin{array}{c}\text { Decil } \\
\text { VIII }\end{array}$ & $\begin{array}{l}\text { Decil } \\
\text { IX }\end{array}$ & $\begin{array}{l}\text { Decil } \\
\mathrm{X}\end{array}$ \\
\hline \multicolumn{13}{|c|}{ GRUPO 1. Fuerte reducción de la pobreza (variación del índice de recuento de la pobreza inferior a $-1,5 \%$ anual) ${ }^{\mathrm{b}}$} \\
\hline \multirow[t]{5}{*}{ Chile } & Y/N 1990 & 2,41 & $\mathbf{0 , 3}$ & 0,5 & $\mathbf{0 , 7}$ & 0,9 & 1,1 & 1,4 & 1,8 & 2,4 & 3,7 & 11,1 \\
\hline & Y/N 2003 & 3,71 & 0,5 & 0,9 & 1,2 & 1,5 & 1,8 & 2,2 & 2,8 & 3,7 & 5,5 & 17,2 \\
\hline & $\Delta \mathrm{Y} / \mathrm{N}(\Delta \mathrm{YL} / \mathrm{O})$ & 0,85 & 0,06 & 0,15 & 0,21 & 0,23 & 0,40 & 0,48 & 0,64 & 0,83 & 1,23 & 4,21 \\
\hline & $\Delta \mathrm{Y} / \mathrm{N}(\Delta \mathrm{O} / \mathrm{N})$ & 0,31 & 0,02 & 0,05 & 0,10 & 0,14 & 0,11 & 0,17 & 0,21 & 0,35 & 0,48 & 1,51 \\
\hline & $\Delta \mathrm{Y} / \mathrm{N}(\Delta \mathrm{YNL} / \mathrm{N})$ & 0,14 & 0,10 & 0,11 & 0,12 & 0,15 & 0,14 & 0,14 & 0,14 & 0,09 & 0,10 & 0,37 \\
\hline \multirow[t]{5}{*}{ Ecuador $^{\mathrm{c}}$} & Y/N 1990 & 1,19 & $\mathbf{0 , 2}$ & 0,4 & 0,5 & 0,6 & $\mathbf{0 , 7}$ & $\mathbf{0 , 9}$ & 1,1 & 1,4 & 1,9 & 4,3 \\
\hline & Y/N 2005 & 1,83 & 0,2 & 0,5 & 0,6 & 0,8 & 1,0 & 1,3 & 1,6 & 2,1 & 2,9 & 7,4 \\
\hline & $\Delta \mathrm{Y} / \mathrm{N}(\Delta \mathrm{YL} / \mathrm{O})$ & 0,27 & $-0,01$ & $-0,02$ & 0,01 & 0,04 & 0,06 & 0,12 & 0,16 & 0,30 & 0,48 & 1,86 \\
\hline & $\Delta \mathrm{Y} / \mathrm{N}(\Delta \mathrm{O} / \mathrm{N})$ & 0,24 & 0,04 & 0,08 & 0,11 & 0,11 & 0,15 & 0,18 & 0,24 & 0,20 & 0,36 & 0,63 \\
\hline & $\Delta \mathrm{Y} / \mathrm{N}(\Delta \mathrm{YNL} / \mathrm{N})$ & 0,13 & 0,03 & 0,02 & 0,04 & 0,05 & 0,04 & 0,08 & 0,11 & 0,19 & 0,22 & 0,64 \\
\hline \multirow[t]{5}{*}{ Brasil } & Y/N 1990 & 2,40 & $\mathbf{0 , 2}$ & $\mathbf{0 , 3}$ & 0,5 & $\mathbf{0 , 7}$ & 0,9 & 1,2 & 1,7 & 2,4 & 4,0 & 12,1 \\
\hline & Y/N 2005 & 2,95 & 0,2 & 0,5 & 0,7 & 1,0 & 1,3 & 1,6 & 2,1 & 2,8 & 4,4 & 15,0 \\
\hline & $\Delta \mathrm{Y} / \mathrm{N}(\Delta \mathrm{YL} / \mathrm{O})$ & $-0,23$ & $-0,01$ & 0,04 & 0,05 & 0,04 & 0,04 & $-0,03$ & $-0,11$ & $-0,25$ & $-0,45$ & $-1,22$ \\
\hline & $\Delta \mathrm{Y} / \mathrm{N}(\Delta \mathrm{O} / \mathrm{N})$ & 0,22 & 0,04 & 0,04 & 0,07 & 0,09 & 0,09 & 0,17 & 0,09 & 0,35 & 0,36 & 0,53 \\
\hline & $\Delta \mathrm{Y} / \mathrm{N}(\Delta \mathrm{YNL} / \mathrm{N})$ & 0,56 & 0,02 & 0,07 & 0,09 & 0,13 & 0,23 & 0,27 & 0,47 & 0,33 & 0,52 & 3,51 \\
\hline \multirow[t]{5}{*}{ Panamá } & Y/N 1991 & 2,17 & 0,2 & 0,4 & 0,6 & 0,8 & 1,0 & 1,3 & 1,8 & 2,4 & 3,6 & 9,5 \\
\hline & Y/N 2005 & 2,68 & 0,2 & 0,5 & 0,8 & 1,0 & 1,4 & 1,8 & 2,3 & 3,2 & 4,7 & 11,0 \\
\hline & $\Delta \mathrm{Y} / \mathrm{N}(\Delta \mathrm{YL} / \mathrm{O})$ & 0,02 & $-0,06$ & $-0,05$ & 0,01 & 0,02 & 0,08 & 0,10 & 0,08 & 0,04 & 0,01 & 0,24 \\
\hline & $\Delta \mathrm{Y} / \mathrm{N}(\Delta \mathrm{O} / \mathrm{N})$ & 0,34 & 0,04 & 0,05 & 0,08 & 0,15 & 0,13 & 0,20 & 0,28 & 0,39 & 0,72 & 1,01 \\
\hline & $\Delta \mathrm{Y} / \mathrm{N}(\Delta \mathrm{YNL} / \mathrm{N})$ & 0,16 & 0,02 & 0,06 & 0,07 & 0,08 & 0,13 & 0,13 & 0,22 & 0,30 & 0,32 & 0,25 \\
\hline \multirow[t]{5}{*}{ México } & Y/N 1989 & 1,87 & $\mathbf{0 , 3}$ & 0,5 & 0,6 & 0,8 & 0,9 & 1,2 & 1,5 & 1,9 & 2,7 & 8,5 \\
\hline & Y/N 2005 & 2,27 & $\mathbf{0 , 3}$ & 0,5 & $\mathbf{0 , 7}$ & 1,0 & 1,2 & 1,5 & 1,9 & 2,4 & 3,4 & 9,8 \\
\hline & $\Delta \mathrm{Y} / \mathrm{N}(\Delta \mathrm{YL} / \mathrm{O})$ & 0,03 & $-0,04$ & $-0,04$ & $-0,01$ & $-0,03$ & 0,01 & $-0,01$ & 0,07 & 0,05 & 0,06 & 0,30 \\
\hline & $\Delta \mathrm{Y} / \mathrm{N}(\Delta \mathrm{O} / \mathrm{N})$ & 0,36 & 0,04 & 0,08 & 0,10 & 0,16 & 0,19 & 0,30 & 0,24 & 0,44 & 0,58 & 1,39 \\
\hline & $\Delta \mathrm{Y} / \mathrm{N}(\Delta \mathrm{YNL} / \mathrm{N})$ & 0,01 & 0,04 & 0,05 & 0,04 & 0,06 & 0,05 & 0,04 & 0,10 & 0,03 & 0,07 & $-0,31$ \\
\hline
\end{tabular}

GRUPO 2. Leve reducción de la pobreza (variación del índice de recuento de la pobreza entre $-1,5 \%$ y $-0,5 \%$ anual) ${ }^{\mathrm{b}}$

\begin{tabular}{|c|c|c|c|c|c|c|c|c|c|c|c|c|}
\hline \multirow[t]{5}{*}{ El Salvador } & Y/N 1995 & 1,42 & 0,1 & 0,3 & 0,5 & 0,7 & 0,8 & 1,0 & 1,3 & 1,6 & 2,3 & 5,6 \\
\hline & Y/N 2004 & 1,55 & $\mathbf{0 , 2}$ & 0,4 & 0,6 & $\mathbf{0 , 7}$ & 0,9 & 1,1 & 1,4 & 1,9 & 2,6 & 5,7 \\
\hline & $\Delta \mathrm{Y} / \mathrm{N}(\Delta \mathrm{YL} / \mathrm{O})$ & 0,00 & $-0,12$ & $-0,03$ & 0,01 & 0,02 & 0,03 & 0,04 & 0,09 & 0,11 & 0,09 & $-0,04$ \\
\hline & $\Delta \mathrm{Y} / \mathrm{N}(\Delta \mathrm{O} / \mathrm{N})$ & 0,06 & 0,01 & 0,04 & 0,02 & 0,05 & 0,06 & 0,01 & 0,03 & 0,09 & 0,05 & 0,00 \\
\hline & $\Delta \mathrm{Y} / \mathrm{N}(\Delta \mathrm{YNL} / \mathrm{N})$ & 0,07 & 0,05 & 0,03 & 0,05 & 0,01 & 0,00 & 0,07 & 0,06 & 0,06 & 0,20 & 0,12 \\
\hline \multirow[t]{5}{*}{ Costa Rica } & Y/N 1990 & 2,17 & $\mathbf{0 , 3}$ & $\mathbf{0 , 7}$ & $\mathbf{0 , 9}$ & 1,2 & 1,5 & 1,8 & 2,2 & 2,8 & 3,6 & 7,0 \\
\hline & Y/N 2005 & 2,78 & 0,4 & 0,8 & 1,1 & 1,4 & 1,7 & 2,1 & 2,6 & 3,4 & 4,7 & 9,8 \\
\hline & $\Delta \mathrm{Y} / \mathrm{N}(\Delta \mathrm{YL} / \mathrm{O})$ & 0,16 & 0,02 & $-0,02$ & $-0,02$ & $-0,02$ & 0,00 & $-0,02$ & $-0,02$ & 0,09 & 0,45 & 1,21 \\
\hline & $\Delta \mathrm{Y} / \mathrm{N}(\Delta \mathrm{O} / \mathrm{N})$ & 0,33 & 0,02 & 0,08 & 0,13 & 0,17 & 0,22 & 0,27 & 0,39 & 0,47 & 0,46 & 0,96 \\
\hline & $\Delta \mathrm{Y} / \mathrm{N}(\Delta \mathrm{YNL} / \mathrm{N})$ & 0,13 & 0,07 & 0,05 & 0,04 & 0,07 & 0,03 & 0,05 & 0,04 & 0,05 & 0,21 & 0,62 \\
\hline \multirow[t]{5}{*}{ Colombia } & Y/N 1991 & 1,52 & 0,2 & 0,4 & 0,5 & 0,6 & $\mathbf{0 , 8}$ & 1,0 & 1,2 & 1,6 & 2,3 & 6,6 \\
\hline & Y/N 2005 & 2,08 & 0,2 & 0,4 & 0,6 & 0,8 & 0,9 & 1,2 & 1,5 & 2,0 & 3,1 & 10,2 \\
\hline & $\Delta \mathrm{Y} / \mathrm{N}(\Delta \mathrm{YL} / \mathrm{O})$ & 0,10 & 0,01 & $-0,01$ & $-0,01$ & 0,01 & 0,03 & 0,06 & 0,06 & 0,12 & 0,26 & 0,55 \\
\hline & $\Delta \mathrm{Y} / \mathrm{N}(\Delta \mathrm{O} / \mathrm{N})$ & 0,06 & $-0,02$ & 0,01 & 0,03 & 0,04 & 0,06 & 0,06 & 0,12 & 0,12 & 0,13 & $-0,12$ \\
\hline & $\Delta \mathrm{Y} / \mathrm{N}(\Delta \mathrm{YNL} / \mathrm{N})$ & 0,41 & 0,03 & 0,04 & 0,05 & 0,05 & 0,05 & 0,07 & 0,10 & 0,16 & 0,37 & 3,18 \\
\hline \multirow[t]{5}{*}{ Guatemala $^{\mathrm{d}}$} & Y/N 1989 & 1,18 & $\mathbf{0 , 1}$ & 0,2 & $\mathbf{0 , 3}$ & 0,4 & 0,5 & $\mathbf{0 , 7}$ & $\mathbf{0 , 9}$ & 1,2 & 1,8 & 5,7 \\
\hline & Y/N 2002 & 1,47 & 0,2 & 0,3 & 0,5 & 0,6 & 0,7 & 0,9 & 1,2 & 1,6 & 2,4 & 6,3 \\
\hline & $\Delta \mathrm{Y} / \mathrm{N}(\Delta \mathrm{YL} / \mathrm{O})$ & 0,00 & 0,03 & 0,02 & $-0,02$ & $-0,03$ & $-0,04$ & $-0,08$ & 0,12 & 0,06 & 0,14 & 0,51 \\
\hline & $\Delta \mathrm{Y} / \mathrm{N}(\Delta \mathrm{O} / \mathrm{N})$ & 0,24 & 0,03 & 0,05 & 0,12 & 0,13 & 0,13 & 0,15 & 0,16 & 0,30 & 0,32 & 0,24 \\
\hline & $\Delta \mathrm{Y} / \mathrm{N}(\Delta \mathrm{YNL} / \mathrm{N})$ & 0,05 & 0,03 & 0,04 & 0,04 & 0,03 & 0,06 & 0,16 & 0,06 & 0,08 & 0,15 & $-0,08$ \\
\hline \multirow[t]{5}{*}{ Nicaragua } & Y/N 1993 & 0,99 & $\mathbf{0 , 0}$ & $\mathbf{0 , 2}$ & $\mathbf{0 , 3}$ & 0,4 & 0,5 & 0,6 & 0,8 & 1,1 & 1,6 & 4,5 \\
\hline & Y/N 2001 & 1,16 & 0,1 & 0,2 & $\mathbf{0 , 3}$ & $\mathbf{0 , 4}$ & 0,6 & $\mathbf{0 , 7}$ & 0,9 & 1,2 & 1,8 & 5,5 \\
\hline & $\Delta \mathrm{Y} / \mathrm{N}(\Delta \mathrm{YL} / \mathrm{O})$ & $-0,06$ & 0,00 & 0,00 & 0,00 & $-0,01$ & $-0,03$ & $-0,11$ & $-0,07$ & $-0,15$ & $-0,18$ & 0,59 \\
\hline & $\Delta \mathrm{Y} / \mathrm{N}(\Delta \mathrm{O} / \mathrm{N})$ & 0,24 & 0,03 & 0,05 & 0,06 & 0,10 & 0,11 & 0,20 & 0,18 & 0,25 & 0,32 & 0,47 \\
\hline & $\Delta \mathrm{Y} / \mathrm{N}(\Delta \mathrm{YNL} / \mathrm{N})$ & $-0,01$ & 0,00 & 0,00 & 0,00 & 0,00 & 0,01 & 0,00 & $-0,02$ & 0,00 & 0,02 & $-0,10$ \\
\hline
\end{tabular}


(continuación)

\begin{tabular}{llccccccccccc}
\hline País & $\begin{array}{c}\text { Ingreso per } \\
\text { cápita (Y/N) }\end{array}$ & Total & $\begin{array}{c}\text { Decil } \\
\text { I }\end{array}$ & $\begin{array}{c}\text { Decil } \\
\text { II }\end{array}$ & $\begin{array}{c}\text { Decil } \\
\text { III }\end{array}$ & $\begin{array}{c}\text { Decil } \\
\text { IV }\end{array}$ & $\begin{array}{c}\text { Decil } \\
\text { V }\end{array}$ & $\begin{array}{c}\text { Decil } \\
\text { VI }\end{array}$ & $\begin{array}{c}\text { Decil } \\
\text { VII }\end{array}$ & $\begin{array}{c}\text { Decil } \\
\text { VIII }\end{array}$ & $\begin{array}{c}\text { Decil } \\
\text { IX }\end{array}$ & $\begin{array}{c}\text { Decil } \\
\text { X }\end{array}$ \\
\hline \multirow{2}{*}{ Honduras } & Y/N 1990 & 0,87 & $\mathbf{0 , 1}$ & $\mathbf{0 , 1}$ & $\mathbf{0 , 2}$ & $\mathbf{0 , 3}$ & $\mathbf{0 , 4}$ & $\mathbf{0 , 5}$ & $\mathbf{0 , 6}$ & $\mathbf{0 , 9}$ & 1,4 & 4,4 \\
& Y/N 2003 & 0,95 & $\mathbf{0 , 1}$ & $\mathbf{0 , 2}$ & $\mathbf{0 , 2}$ & $\mathbf{0 , 3}$ & $\mathbf{0 , 4}$ & $\mathbf{0 , 6}$ & $\mathbf{0 , 8}$ & 1,1 & 1,6 & 4,4 \\
& $\Delta$ Y/N $(\Delta$ YL/O) & $-0,13$ & 0,00 & $-0,02$ & $-0,02$ & $-0,02$ & $-0,05$ & $-0,03$ & $-0,05$ & $-0,10$ & $-0,11$ & $-0,68$ \\
& $\Delta$ Y/N $(\Delta$ O/N) & 0,09 & 0,00 & 0,02 & 0,03 & 0,06 & 0,06 & 0,06 & 0,06 & 0,10 & 0,14 & 0,07 \\
& $\Delta$ Y/N $(\Delta$ YNL/N) & 0,13 & 0,02 & 0,02 & 0,03 & 0,02 & 0,06 & 0,06 & 0,13 & 0,19 & 0,18 & 0,52
\end{tabular}

GRUPO 3. Sin progresos (variación del índice de recuento de la pobreza entre $-0,5 \%$ y $0,5 \%$ anual) ${ }^{\mathrm{b}}$

\begin{tabular}{|c|c|c|c|c|c|c|c|c|c|c|c|c|}
\hline Venezuela & Y/N 1990 & 1,80 & 0,3 & 0,5 & 0,7 & 0,9 & 1,1 & 1,4 & 1,7 & 2,2 & 3,0 & 6,5 \\
\hline \multirow[t]{4}{*}{ (Rep. Bol. de) } & Y/N 2005 & 1,97 & 0,2 & 0,5 & $\mathbf{0 , 7}$ & 1,0 & 1,2 & 1,5 & 1,9 & 2,4 & 3,2 & 7,2 \\
\hline & $\Delta \mathrm{Y} / \mathrm{N}(\Delta \mathrm{YL} / \mathrm{O})$ & $-0,13$ & $-0,06$ & $-0,07$ & $-0,08$ & $-0,11$ & $-0,11$ & $-0,10$ & $-0,07$ & $-0,08$ & $-0,07$ & 0,11 \\
\hline & $\Delta \mathrm{Y} / \mathrm{N}(\Delta \mathrm{O} / \mathrm{N})$ & 0,34 & 0,06 & 0,12 & 0,19 & 0,22 & 0,28 & 0,30 & 0,28 & 0,31 & 0,32 & 0,60 \\
\hline & $\Delta \mathrm{Y} / \mathrm{N}(\Delta \mathrm{YNL} / \mathrm{N})$ & $-0,03$ & $-0,09$ & $-0,06$ & $-0,07$ & $-0,06$ & $-0,06$ & $-0,06$ & $-0,04$ & $-0,03$ & 0,02 & 0,04 \\
\hline \multirow[t]{5}{*}{ Bolivia $^{\mathrm{e}}$} & Y/N 1989 & 1,67 & $\mathbf{0 , 1}$ & $\mathbf{0 , 4}$ & $\mathbf{0 , 5}$ & $\mathbf{0 , 7}$ & 0,9 & 1,1 & 1,4 & 1,9 & 2,8 & 7,0 \\
\hline & Y/N 2004 & 1,71 & $\mathbf{0 , 3}$ & 0,5 & 0,6 & 0,7 & $\mathbf{0 , 9}$ & 1,1 & 1,3 & 1,8 & 2,7 & 7,3 \\
\hline & $\Delta \mathrm{Y} / \mathrm{N}(\Delta \mathrm{YL} / \mathrm{O})$ & $-0,38$ & 0,01 & $-0,07$ & $-0,10$ & $-0,10$ & $-0,19$ & $-0,24$ & $-0,35$ & $-0,45$ & $-0,58$ & $-1,10$ \\
\hline & $\Delta \mathrm{Y} / \mathrm{N}(\Delta \mathrm{O} / \mathrm{N})$ & 0,21 & 0,13 & 0,11 & 0,10 & 0,09 & 0,14 & 0,14 & 0,15 & 0,10 & 0,20 & 0,27 \\
\hline & $\Delta \mathrm{Y} / \mathrm{N}(\Delta \mathrm{YNL} / \mathrm{N})$ & 0,21 & 0,00 & 0,03 & 0,05 & 0,06 & 0,07 & 0,08 & 0,16 & 0,26 & 0,31 & 1,13 \\
\hline \multirow[t]{5}{*}{ Argentina ${ }^{\mathrm{f}}$} & Y/N 1990 & 3,10 & 0,5 & 0,8 & 1,1 & 1,4 & 1,8 & 2,2 & 2,7 & 3,5 & 4,8 & 12,2 \\
\hline & Y/N 2005 & 3,14 & 0,4 & 0,8 & 1,1 & 1,4 & 1,7 & 2,1 & 2,6 & 3,4 & 4,8 & 13,1 \\
\hline & $\Delta \mathrm{Y} / \mathrm{N}(\Delta \mathrm{YL} / \mathrm{O})$ & $-0,27$ & $-0,15$ & $-0,14$ & $-0,11$ & $-0,09$ & $-0,06$ & $-0,22$ & $-0,33$ & $-0,45$ & $-0,62$ & $-0,12$ \\
\hline & $\Delta \mathrm{Y} / \mathrm{N}(\Delta \mathrm{O} / \mathrm{N})$ & 0,28 & 0,06 & 0,15 & 0,12 & 0,25 & 0,04 & 0,09 & 0,15 & 0,23 & 0,60 & 0,76 \\
\hline & $\Delta \mathrm{Y} / \mathrm{N}(\Delta \mathrm{YNL} / \mathrm{N})$ & 0,02 & $-0,02$ & $-0,04$ & $-0,03$ & $-0,16$ & $-0,01$ & 0,05 & 0,07 & 0,10 & 0,02 & 0,25 \\
\hline \multirow[t]{5}{*}{ Uruguay $^{\mathrm{c}}$} & Y/N 1990 & 3,09 & 0,6 & $\mathbf{0 , 9}$ & 1,2 & 1,5 & 1,8 & 2,2 & 2,6 & 3,2 & 4,3 & 12,7 \\
\hline & Y/N 2005 & 2,77 & $\mathbf{0 , 5}$ & $\mathbf{0 , 8}$ & 1,1 & 1,4 & 1,8 & 2,1 & 2,6 & 3,3 & 4,5 & 9,6 \\
\hline & $\Delta \mathrm{Y} / \mathrm{N}(\Delta \mathrm{YL} / \mathrm{O})$ & $-0,36$ & $-0,10$ & $-0,14$ & $-0,11$ & $-0,15$ & $-0,13$ & $-0,08$ & $-0,10$ & $-0,07$ & 0,20 & $-2,71$ \\
\hline & $\Delta \mathrm{Y} / \mathrm{N}(\Delta \mathrm{O} / \mathrm{N})$ & 0,00 & 0,00 & 0,01 & 0,01 & 0,04 & 0,05 & 0,01 & $-0,02$ & $-0,03$ & $-0,08$ & $-0,16$ \\
\hline & $\Delta \mathrm{Y} / \mathrm{N}(\Delta \mathrm{YNL} / \mathrm{N})$ & 0,03 & 0,05 & 0,04 & 0,02 & 0,04 & 0,04 & 0,05 & 0,12 & 0,17 & 0,09 & $-0,24$ \\
\hline \multicolumn{13}{|c|}{ GRUPO 4. Aumento de la pobreza (variación del índice de recuento de la pobreza superior a $0,5 \%$ anual) } \\
\hline \multirow[t]{5}{*}{ Paraguayg } & Y/N 1990 & 1,69 & 0,3 & 0,5 & 0,7 & $\mathbf{0 , 9}$ & 1,1 & 1,2 & 1,5 & 2,0 & 2,8 & 5,9 \\
\hline & Y/N 2005 & 1,67 & $\mathbf{0 , 3}$ & 0,5 & 0,6 & $\mathbf{0 , 8}$ & 0,9 & 1,2 & 1,4 & 1,8 & 2,6 & 6,6 \\
\hline & $\Delta \mathrm{Y} / \mathrm{N}(\Delta \mathrm{YL} / \mathrm{O})$ & $-0,21$ & $-0,11$ & $-0,13$ & $-0,19$ & $-0,13$ & $-0,18$ & $-0,27$ & $-0,27$ & $-0,42$ & $-0,50$ & $-0,14$ \\
\hline & $\Delta \mathrm{Y} / \mathrm{N}(\Delta \mathrm{O} / \mathrm{N})$ & 0,09 & 0,02 & 0,03 & 0,05 & $-0,04$ & $-0,02$ & 0,11 & 0,08 & 0,10 & 0,11 & 0,62 \\
\hline & $\Delta \mathrm{Y} / \mathrm{N}(\Delta \mathrm{YNL} / \mathrm{N})$ & 0,10 & 0,04 & 0,05 & 0,07 & 0,06 & 0,08 & 0,09 & 0,08 & 0,13 & 0,14 & 0,24 \\
\hline
\end{tabular}

Fuente: elaboración propia, sobre la base de las encuestas de hogares de los respectivos países.

* Las cifras en negrita y destacadas en color gris señalan los deciles cuyos ingresos per cápita se encuentran por debajo de la línea de pobreza $(<1,0)$. Los países están ordenados según su nivel de pobreza en el período 2001/2005, desde los menos pobres hasta los más pobres.

a Los componentes de la variación del ingreso per cápita que se deben a cambios en el ingreso laboral por ocupado $\Delta Y / N(\Delta Y L / O)$, a cambios en la tasa global de ocupación $\Delta Y / N(\Delta O / N)$ y a cambios en el ingreso no laboral per cápita $\Delta Y / N(\Delta Y N L / N$ (en múltiplos de la línea de pobreza), se calcularon según la fórmula 3.

b La variación anual del índice de recuento de la pobreza para cada país, que permitió la clasificación de los países en grupos, se estimó sobre la base de la fórmula $V A P=[((P F-P I) / P I) * 100] / A$, donde $V A P=$ variación anual de la pobreza, $P F=$ porcentaje de pobreza final, $P I=$ porcentaje de pobreza inicial y $A=$ número de años contenidos en el período.

c Áreas urbanas.

d En el caso de Guatemala, el número de deciles con ingreso per cápita inferior a la línea de pobreza es superior a lo que correspondería por los niveles de pobreza incluidos en los números pertinentes del Panorama social de América Latina que publica la CEPAL. Esto se debe a ajustes en el procesamiento de los datos que se hicieron necesarios para enfrentar la ausencia de mediciones que incluyeran la población menor de diez años en 1989 y de siete años en el 2002.

e Cochabamba, El Alto, La Paz, Oruro, Potosí, Santa Cruz, Tarija y Trinidad.

f Gran Buenos Aires.

g Área Metropolitana de Asunción. 
América Latina (16 países): tipología de países según las tendencias de la tasa global de ocupación, ingresos laborales por ocupado e ingresos no laborales en los deciles que incluyen hogares pobres, 1989/1995 a 2001/2005

\begin{tabular}{|c|c|c|c|c|c|}
\hline $\begin{array}{l}\text { Tendencia de la pobreza } \\
\text { (promedio anual) }\end{array}$ & $\begin{array}{l}\text { Pobreza } \\
\text { inicial } \\
(\%)^{\mathrm{a}}\end{array}$ & $\begin{array}{c}\text { Tasa global } \\
\text { de ocupación } \\
(\mathrm{O} / \mathrm{N})\end{array}$ & $\begin{array}{l}\text { Ingresos laborales } \\
\text { por ocupado } \\
\text { (YL/O) }\end{array}$ & $\begin{array}{c}\text { Ingresos no } \\
\text { laborales per cápita } \\
(\mathrm{YNL} / \mathrm{N})\end{array}$ & $\begin{array}{l}\text { Pobreza } \\
\text { final } \\
(\%)^{\mathrm{a}}\end{array}$ \\
\hline \multicolumn{6}{|c|}{ Fuerte reducción (variación inferior a $-1,5 \%$ anual) } \\
\hline Chile, 1990-2003 & 38,3 & ++ & ++ & ++ & 18,6 \\
\hline Ecuador, 1990-2005 & 61,8 & ++ & + & + & 45,1 \\
\hline Brasil, 1990-2005 & 47,4 & ++ & + & ++ & 36,2 \\
\hline Panamá, 1991-2005 & 42,8 & ++ & - & + & 32,7 \\
\hline México, 1989-2005 & 47,4 & ++ & - & + & 35,5 \\
\hline \multicolumn{6}{|c|}{ Leve reducción (variación entre $-1,5 \%$ y - 0,5\% anual) } \\
\hline El Salvador, 1995-2004 & 54,0 & + & - & + & 47,5 \\
\hline Costa Rica, 1990-2005 & 26,2 & + & +- & + & 21,1 \\
\hline Colombia, 1991-2005 & 55,6 & + & $=$ & + & 46,8 \\
\hline Guatemala, 1989-2002 & 70,3 & ++ & $=$ & ++ & 58,4 \\
\hline Nicaragua, 1993-2001 & 73,6 & ++ & -- & $=$ & 69,3 \\
\hline Honduras, $1990-2003$ & 80,5 & ++ & -- & ++ & 74,6 \\
\hline \multicolumn{6}{|c|}{ Sin progresos (variación entre $-0,5 \%$ y $0,5 \%$ anual) } \\
\hline Venezuela (Rep. Bol. de), 1990-2005 & 40,0 & ++ & -- & - & 37,1 \\
\hline Bolivia, 1989-2004 & 52,1 & ++ & -- & + & 51,6 \\
\hline Argentina, 1990-2005 & 21,1 & + & - & $=$ & 22,6 \\
\hline Uruguay, $1990-2005$ & 17,8 & $=$ & - & + & 19,1 \\
\hline \multicolumn{6}{|c|}{ Aumento (variación superior a $0,5 \%$ anual) } \\
\hline Paraguay, 1990-2005 & 42,2 & +- & -- & + & 47,7 \\
\hline \multicolumn{6}{|l|}{ Leyenda: } \\
\hline++ & \multicolumn{5}{|c|}{ Avance significativo } \\
\hline+ & \multicolumn{5}{|c|}{ Avance } \\
\hline$=1+-$ & \multicolumn{5}{|c|}{ Sin cambios/avances y retrocesos } \\
\hline- & \multicolumn{5}{|c|}{ Retroceso } \\
\hline-- & \multicolumn{5}{|c|}{ Retroceso significativo } \\
\hline
\end{tabular}

Fuente: elaboración propia, sobre la base de las encuestas de hogares de los respectivos países.

a Estos porcentajes pueden no coincidir con los presentados en los números correspondientes del Panorama social de América Latina que publica la CEPAL, debido al distinto tratamiento del servicio doméstico. En el caso de Guatemala, se trata de ajustes en el procesamiento de datos que se hicieron necesarios para enfrentar la ausencia de mediciones que incluyeran la población menor de diez años en 1989 y de siete años en el 2002.

urbanas de Ecuador), así como México y Panamá, donde la proporción de ocupados aumentó significativamente. Tanto en México como en Panamá la tasa de participación femenina subió sustancialmente, y en el caso panameño fue además acompañada por una fuerte disminución de la tasa de desempleo. Los países restantes no exhibieron progresos, o estos fueron muy leves, siendo su principal limitante el magro desempeño de sus mercados de trabajo. En los países con fuerte reducción de la pobreza, el principal factor del cambio fue el comportamiento de las familias respecto a su composición y la participación de las mujeres en el mercado de trabajo. Si bien estos fenómenos son bastante generalizados en todos los otros países, tales esfuerzos no han sido acompañados en ellos por aumentos de la productividad ni de las transferencias hacia las familias.

\section{El mercado de trabajo como factor de las diferen- cias en las tendencias de pobreza entre países}

Si se comparan los países con mayor y menor disminución de la pobreza, destaca en los resultados el comportamiento relativo al mercado de trabajo (gráfico 3). Como muestra la sección A del gráfico, en Brasil, Chile y las áreas urbanas de Ecuador el aumento de la razón ocupados/población total (barras gris claro) se ha complementado con un incremento del ingreso laboral por ocupado (barras negras), lo que implica un fuerte dinamismo de sus mercados de trabajo. A esto se agrega un aumento de los ingresos no laborales (barras gris oscuro). Todo ello concurre en un importante crecimiento del ingreso de las familias en estos países y, por ende, una menor incidencia de la pobreza. Así lo sugiere el desplazamiento de la curva de 
Factores determinantes de cambios en la incidencia de la pobreza, deciles I-IX, 1990-2005a

A. Países con fuerte reducción de la pobreza y aumentos de la productividad laboral (Brasil, Chile y áreas urbanas de Ecuador, promedio simple)

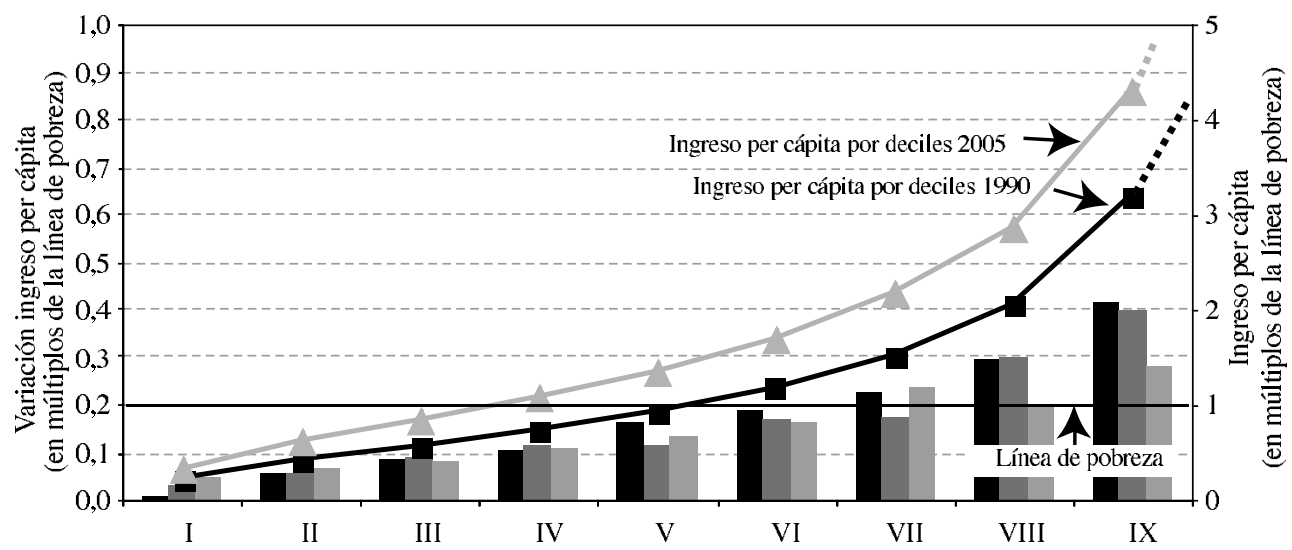

Deciles de ingreso

Variación del ingreso per cápita por cambios en el ingreso laboral por ocupado (1990-2005)

Variación del ingreso per cápita por cambios en la tasa global de ocupación (1990-2005)

Variación del ingreso per cápita por cambios en el ingreso no laboral per cápita (1990-2005)

-Ingreso per cápita 1990

- Ingreso per cápita 2005

B. Países sin progresos o con aumento de la pobreza (Argentina, Bolivia,

Paraguay, Uruguay y Rep. Bolivariana de Venezuela, promedio simple)

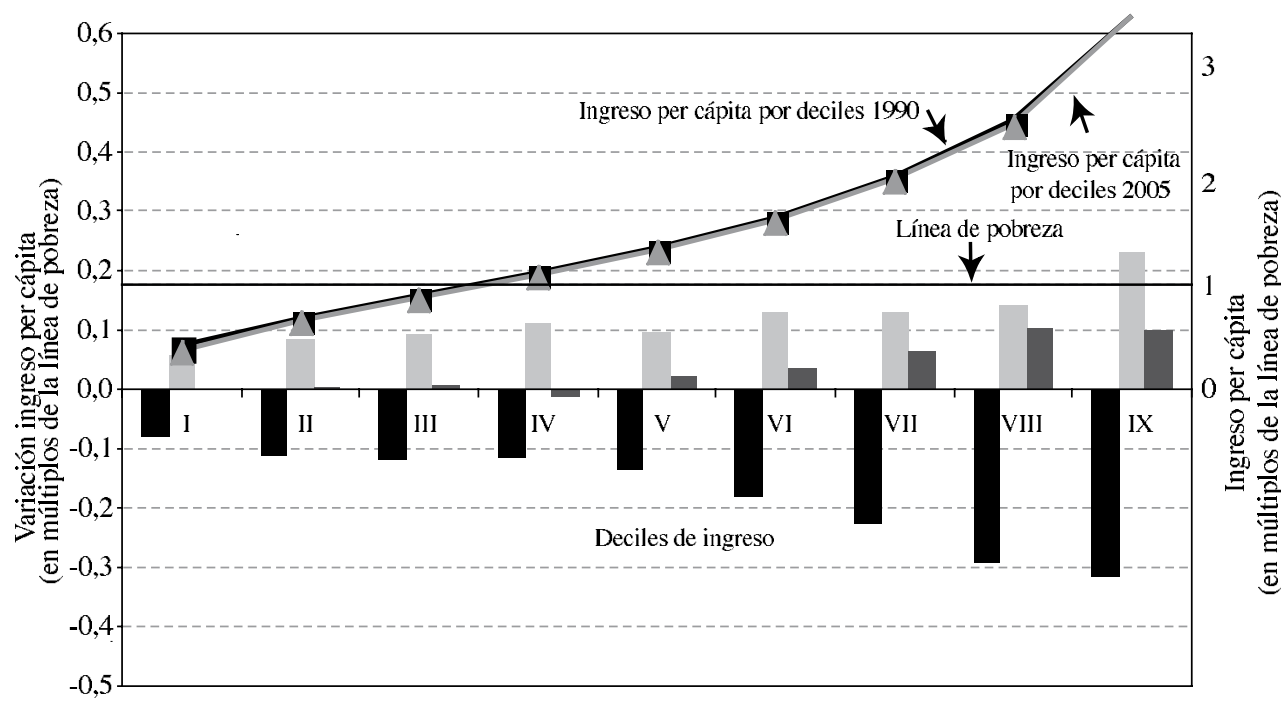

Fuente: elaboración propia, sobre la base de las encuestas de hogares de los respectivos países.

a Años alrededor de 1990 y de 2005. 
la distribución del ingreso per cápita hacia la izquierda entre 1990 (curva negra) y 2005 (curva gris), que cruza la línea de pobreza en deciles más bajos de la distribución del ingreso. En Argentina (Gran Buenos Aires), Bolivia, Paraguay (Área Metropolitana de Asunción), Uruguay (áreas urbanas) y la República Bolivariana de Venezuela, en cambio, los ingresos laborales por ocupado decrecieron entre los pobres, y esa disminución no fue suficientemente compensada por mejoras en la tasa de ocupación global o en los ingresos no laborales. Por lo mismo, no hubo progresos en la reducción de la pobreza.

El gráfico 3 ilustra además tres aspectos importantes del análisis. De partida, mientras menos desigual sea la distribución del ingreso per cápita de las familias - hecho que se observa cuando las correspondientes curvas son menos inclinadas - mayor será la reducción de la pobreza ante aumentos de los ingresos por ocupado o ante transferencias del Estado.

En segundo lugar, se aprecia en el gráfico que en torno al 2005 quienes tienen ingresos per cápita inferiores a la línea de pobreza en los países considerados constituyen alrededor de un tercio de la población, pero que son muchos más los que viven en situación de vulnerabilidad, con ingresos apenas superiores a esa línea, lo que no les permitiría hacer frente a situaciones de crisis. ${ }^{12}$ Una observación similar se puede hacer para los demás países de la región, ya que en ningún país de América Latina el quinto decil de la distribución tiene un ingreso per cápita medio que sea igual o superior a dos veces la línea de pobreza (cuadro 1).

En tercer lugar se ve que, medida como proporción de la línea de pobreza, la variación del ingreso laboral por ocupado reproduce el perfil de la distribución del ingreso, siendo sustancialmente mayor para los deciles más altos. Esto es consistente con la hipótesis de que los incrementos de productividad se originan en empresas formales, benefician de preferencia a trabajadores insertos en esas empresas y se distribuyen en forma proporcional a los niveles precedentes de ingreso, de modo que no contienen en sí componentes redistributivos sino que se propagan lentamente conforme a la escala salarial.

\section{El fenómeno de los trabajadores pobres}

Finalmente, cabe destacar que el actual funcionamiento del mercado de trabajo en la región no permite salir de la pobreza a amplios segmentos de trabajadores. En las áreas urbanas de América Latina, entre 10\% (Chile) y $54 \%$ (Nicaragua y Honduras) de los ocupados vive en condiciones de pobreza (gráfico 4), y en las áreas rurales

GRÁFICO 4

América Latina (16 países): porcentaje de ocupados pobres, ${ }^{a}$ 1990-2005

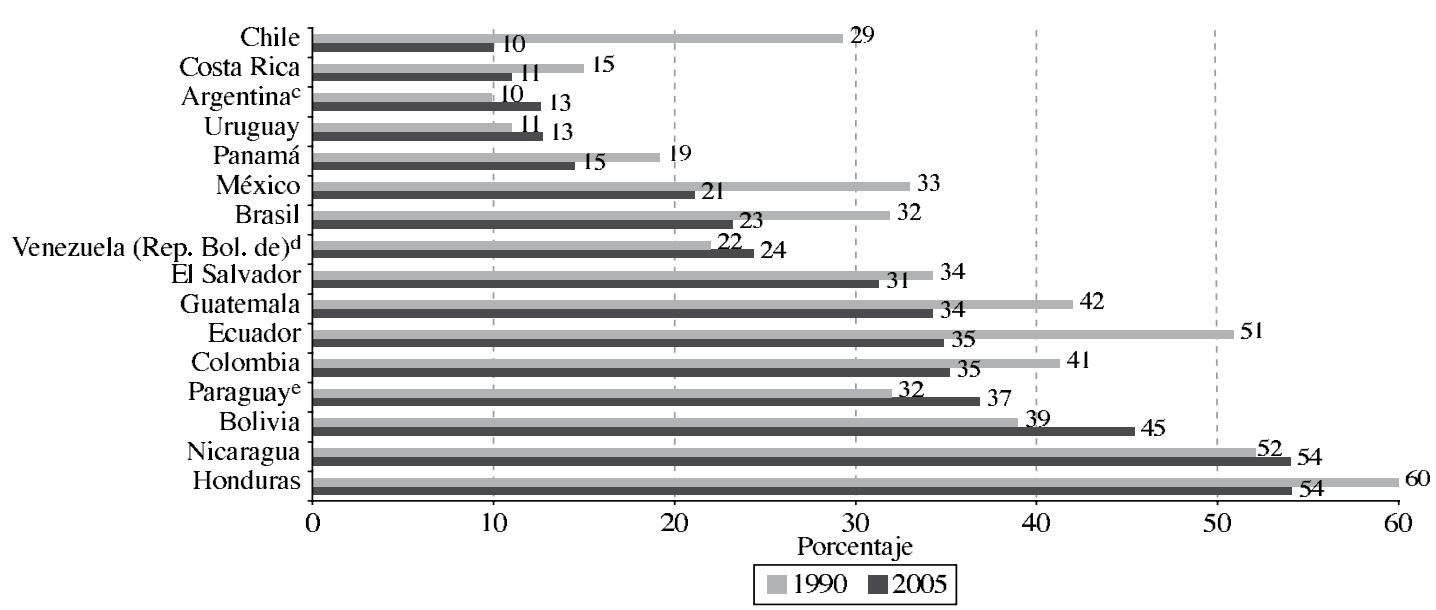

Fuente: elaboración propia, sobre la base de las encuestas de hogares de los respectivos países.

a Se refiere al porcentaje de ocupados que reside en hogares con ingresos inferiores a la línea de pobreza.

b Años alrededor de 1990 y de 2005.

c Gran Buenos Aires.

d A partir de 1997 el diseño muestral de la encuesta no permite el desglose urbano-rural. Por lo tanto, las cifras corresponden al total nacional

e Áreas urbanas: corresponde al Área Metropolitana de Asunción.

12 En el gráfico 3 la pendiente de la curva del ingreso per cápita se hace más pronunciada a partir del octavo decil, lo cual significa que existe un $70 \%$ de la población cuyos niveles de subsistencia son muy vulnerables. 
el porcentaje de ocupados pobres es aún más alto, pues varía entre $11 \%$ (Chile) y $81 \%$ (Honduras). Como es de esperar, en los países donde los ingresos laborales de las familias más pobres aumentaron significativamente en el período 1990-2005 (Chile, Brasil y áreas urbanas de Ecuador) disminuyó el porcentaje de ocupados que viven por debajo de la línea de pobreza, mientras que aumentó en aquellos países donde los ingresos laborales descendieron: Argentina (áreas urbanas), Bolivia, Paraguay,
República Bolivariana de Venezuela y Uruguay. Es por lo tanto imperativo mejorar la calidad de la inserción de amplios sectores de la fuerza laboral, y en particular de los más pobres, en el mercado de trabajo. Esto, en concreto, significaría proveer salarios suficientes, contratos estables, condiciones de trabajo seguras (en cuanto a accidentes y enfermedades laborales), acceso a los sistemas y seguros de salud y afiliación y aporte a los sistemas de previsión social (CEPAL, 2007a).

\section{IV}

\section{Reflexiones sobre el bono demográfico y los desafíos a las políticas públicas}

Para reducir la pobreza, los países de América Latina se han beneficiado - y aún pueden beneficiarse- del decrecimiento de la relación de dependencia demográfica, ya que para cada persona en edad de trabajar hay una menor carga derivada de las necesidades de niños y ancianos. Esta situación — conocida como "bono demográfico"- es particularmente favorable, porque al interior de los hogares un menor número de dependientes por cada miembro económicamente activo puede significar un aumento del ingreso per cápita.

Sin embargo, el bono demográfico está acotado temporalmente, ya que la menor fecundidad y los incrementos de la longevidad acrecientan el peso de las personas mayores; en consecuencia, la relación de dependencia se eleva nuevamente, esta vez generando otras demandas de atención de salud y seguridad económica. Puede decirse que el momento en que se produce este aumento de la relación de dependencia marca el fin del bono demográfico. ${ }^{13}$

Pese a que dicho bono demográfico puede extenderse en la medida en que las personas en edades activas —en particular las mujeres_- aumentan su participación en la actividad económica, muchos de sus dividendos no están garantizados, pues dependen de la capacidad de las economías de la región para generar empleo cuando esto ocurre, de la capacidad de los pobres de encontrar empleos que proporcionen buenos ingresos

\footnotetext{
13 No obstante, algunos autores han avanzado la hipótesis de la existencia de un "segundo bono demográfico", que se daría gracias a que el proceso de envejecimiento de las sociedades provee mayores incentivos para el ahorro, estimulando así la inversión y el crecimiento (Mason y Lee, 2004).
}

y cobertura de protección social, y también de la forma como se organizan en términos de composición familiar frente a las contingencias. Así, para aprovechar el bono demográfico es preciso atender a la oferta laboral de una población activa en aumento y, simultáneamente, disminuir la inseguridad, la precariedad y la informalidad típicas de los mercados laborales de la región.

En particular, si bien las familias más pobres necesitan captar mayores ingresos, hay factores que limitan y desincentivan su participación laboral. Su baja dotación de capital humano disminuye las oportunidades de trabajo de sus miembros y aumenta la probabilidad de que queden desempleados o generen bajos ingresos laborales. A su vez, las más altas tasas de fecundidad y de dependencia, unidas a la necesidad de ocuparse del cuidado familiar, limitan aún más la participación de las mujeres en el mercado de trabajo, así como las inversiones en capital humano.

Aunque hay países que han logrado reducir la pobreza desde principios de los 1990, gracias a los efectos del bono demográfico y a incrementos de los ingresos por ocupado - Chile, Brasil y Ecuador (áreas urbanas) los resultados obtenidos a la fecha generalmente no han sido muy alentadores. Ellos deben analizarse teniendo en cuenta que la situación favorable al desarrollo y la reducción de la pobreza creada por el bono demográfico terminará por revertirse.

El término del bono demográfico tendrá efectos importantes en todos los países de la región, particularmente en los que redujeron la pobreza gracias únicamente a aumentos de la razón población en edad de trabajar/población total o de la tasa de participación, sin mejorar significativamente el empleo y los ingresos 
por ocupado, así como en aquellos donde la pobreza subió. Alrededor del 2010, Cuba será el primer país de América Latina en el que se acabe el bono demográfico, seguido por Chile y Costa Rica (alrededor del 2015) y sucesivamente por Brasil, Colombia, México y Uruguay (alrededor del 2020).

Si bien se ha avanzado en el cumplimiento de la primera meta del Milenio - en gran medida como resultado del bono demográfico- no es menos cierto que aún son insuficientes los incrementos de los ingresos laborales y de las oportunidades de empleo para los más pobres.

Para seguir reduciendo la pobreza en los países de América Latina se necesitarán políticas públicas activas destinadas a conciliar el cuidado del hogar con el trabajo remunerado, a mejorar la productividad en las ocupaciones en las cuales se desempeñan los miembros de los hogares más pobres y, en la eventualidad de que esto no ocurra, a focalizar el gasto social en las demandas de estos grupos más necesitados. Por lo mismo, es fundamental elevar a rango de política pública las acciones que permitan, sobre todo en los hogares pobres, ayudar a las mujeres a conciliar el cuidado de los dependientes con la actividad remunerada, con el fin de elevar su tasa de participación. También es necesario que las mujeres ejerzan plenamente los derechos reproductivos para poder decidir sobre el tamaño de sus hogares y la dinámica familiar en el ciclo de vida. Todo esto debe complementarse con políticas masivas y pertinentes de capacitación laboral y reinserción ocupacional para la población activa de baja productividad, a fin de que pueda ubicarse en el mundo laboral con mejores opciones.

Estas demandas que se plantean a las estrategias de desarrollo socioeconómico de los países no son nuevas. Sin embargo, con el creciente envejecimiento de las poblaciones se harán cada vez más apremiantes, dado que una vez que el efecto del bono demográfico culmine las tendencias demográficas no contribuirán a elevar el ingreso per cápita.

El desafío que se enfrenta no se da en un vacío. Es preciso buscar respuestas que concilien tres grandes transformaciones de las que la política pública debe hacerse cargo: aquellas que responden a inercias demográficas, como el envejecimiento de la población y la baja de la natalidad; aquellas que dependen del desempeño de los agentes económicos, como las mejoras de productividad en contextos internacionales muy competitivos, y aquellas de economía política que se refieren al papel y tamaño del Estado.

\section{Bibliografía}

Arriagada, I. (2004): Estructuras familiares, trabajo y bienestar en América Latina, en I. Arriagada y V. Aranda (comps.), Cambio de las familias en el marco de las transformaciones globales: necesidad de políticas públicas eficaces, serie Seminarios y conferencias, No 42, LC/L.2230-P, Santiago de Chile, Comisión Económica para América Latina y el Caribe (CEPAL). Publicación de las Naciones Unidas, $\mathrm{N}^{\mathrm{o}}$ de venta: S.04.II.G.150.

CEPAL (Comisión Económica para América Latina y el Caribe) (2003): Panorama social de América Latina 2002-2003, LC/G.2209-P, Santiago de Chile. Publicación de las Naciones Unidas, $\mathrm{N}^{\circ}$ de venta: S.03.II.G.185.

(2005a): Objetivos de desarrollo del Milenio. Una mirada desde América Latina y el Caribe, LC/G.2331-P, Santiago de Chile. Publicación de las Naciones Unidas, $N^{o}$ de venta: S.05. II.G.107.

(2005b): Panorama social de América Latina 2005, LC/G.2326-P, Santiago de Chile. Publicación de las Naciones Unidas, $\mathrm{N}^{\circ}$ de venta: S.06.II.G.133.

(2006): La protección social de cara al futuro: Acceso, financiamiento y solidaridad, LC/G.2294 (SES.31/3), marzo, Santiago, Chile.

(2007a): Panorama social de América Latina 2006, LC/G.2326-P, Santiago de Chile. Publicación de las Naciones Unidas, $\mathrm{N}^{\circ}$ de venta: S.06.II.G.133.

(2007b): Balance preliminar de las economías de América Latina y el Caribe 2007, LC/G.2355-P, Santiago de Chile. Publicación de las Naciones Unidas, $\mathrm{N}^{\circ}$ de venta: S.07. II.G.161. (2007c): Cohesión social: inclusión y sentido de pertenencia en América Latina y el Caribe, LC/G.2335/Rev.1, Santiago de Chile.

(2007d): Panorama social de América Latina 2007, LC/G.2351-P, Santiago de Chile.

(2008a): Superar la pobreza mediante la inclusión social, LC/W.174, Santiago de Chile.

Islam, R. (2004): The Nexus of Economic Growth, Employment and Poverty Reduction: An Empirical Analysis, Issues in Employment and Poverty Discussion Paper, $N^{\circ} 14$, Ginebra, Organización Internacional del Trabajo.

Kakwani, N., M. Neri. y H.H. Son (2006): Linkages Between Pro-poor growth, Social Programmes and Labour Market: the Recent Brazilian Experience, International Poverty Centre Working Paper, No 26 , agosto, Brasilia, Centro Internacional de la Pobreza.

Mason, A. y R. Lee (2004): Reform and support systems for the elderly in developing countries: capturing the second demographic dividend, documento presentado en el International Seminar on the Demographic Window and Healthy Aging: Socioeconomic Challenges and Opportunities, Beijing, China Centre for Economic Research, Peking University.

Navarrete, M. (2005): Clasificación económica de la población: indicadores sobre empleo y nivel de actividad, Montevideo, Universidad de la República.

Núñez, J., J.C. Ramírez y L. Cuesta (2006): Determinantes de la pobreza en Colombia, 1996-2004, serie Estudios y perspectivas, $\mathrm{N}^{\circ}$ 13, LC/L.2579-P, Bogotá, D.C., Oficina de la CEPAL en Bogotá. Publicación de las Naciones Unidas, $\mathrm{N}^{\circ}$ de venta: S.06.II.G.109. 
OIT (Organización Internacional del Trabajo) (2004): Informe sobre el empleo en el mundo 2004-2005, Ginebra.

(2006): Panorama laboral 2006, Lima, Oficina Regional para América Latina y el Caribe.

(2007): Panorama Laboral 2007, Lima, Oficina Regional para América Latina y el Caribe, Perú.

Osmani, S.R. (2002): Exploring the employment nexus: topics in employment and poverty, documento preparado para el equipo de tareas sobre el programa conjunto OIT/PNUD sobre empleo y pobreza, Nueva York.

Sen, A. (1985): El bienestar, la condición de ser agente y la libertad. Conferencias Dewey de 1984, Bienestar, justicia y mercado, Barcelona, Paidós.
Sunkel, G. (2006): El papel de la familia en la protección social en América Latina, serie Políticas sociales, N ${ }^{\circ} 120$, LC/L.2530-P, Santiago de Chile, Comisión Económica para América Latina y el Caribe (CEPAL). Publicación de las Naciones Unidas, $\mathrm{N}^{\mathrm{o}}$ de venta: S.06.II.G.57.

Uthoff, A., C. Vera y N. Ruedi (2006): Relación de dependencia del trabajo formal y brechas de protección social en América Latina y el Caribe, en A. Sojo y A. Uthoff (comps.), Desempeño económico y política social en América Latina y el Caribe: los retos de la equidad, el desarrollo y la ciudadanía, México, D.F., CEPAL/FLACSO/Distribuciones Fontamara.

Weller, J. (2006): Los jóvenes y el empleo en América Latina: desafíos y perspectivas ante el nuevo escenario laboral, Bogotá, D.C., CEPAL/Mayol ediciones. 